\title{
LINGUÍSTICA SISTÊMICO-FUNCIONAL PARA A ANÁLISE DE DISCURSO UM PANORAMA INTRODUTÓRIO
}

\author{
(Systemic functional linguistics for discourse analysis: \\ an introductory overview)
}

\author{
Leila Barbara \\ (PUC-SP/LAEL/CNPq) \\ Célia Maria Macêdo de Macêdo \\ (Universidade Federal do Pará- UFPA)
}

\begin{abstract}
This paper presents an overview of Systemic-Functional Linguistics of Halliday (1994) and Halliday and Matthiessen (2004), characterizing it as a social theory as it takes society and the situation of use for the study of language, and also as a semiotic theory due to its concern with every manifestation of language. It explains the three metafunctions that cover the three meanings that can be actualized by language, emphasizing the relationship there is between text and context. Each metafunction is then illustrated with papers that have analysed corpus of different contexts of situation.
\end{abstract}

Key words: systemic-functional linguistics; metafunctions; society; context

\section{RESUMO}

Este artigo apresenta um panorama da Lingüística Sistêmico-Funcional de Halliday (1994) e Halliday e Matthiessen (2004), explicando que é caracterizada como uma teoria social porque parte da sociedade e da situação de uso para o estudo da linguagem e também como uma teoria semiótica porque se preocupa com a linguagem em todas as suas manifestações. As três metafunções que abarcam os três significados realizados pela linguagem são explicados, enfatizando-se a relação que há entre texto e contexto. Cada metafunção é ilustrada com exemplos de trabalhos que analisaram corpus de diferentes contextos de situação. 
Palavras-chave: linguística sistêmico-funcional; metafunções; sociedade; contexto

\section{Introdução}

Este artigo traz uma visão dos princípios norteadores da Linguística Sistêmico Funcional (doravante LSF) de Halliday (1994) e Halliday e Matthiessen (2004), tendo como preocupação principal mostrar a importância de se ter uma gramática funcional como base em investigações linguísticas no campo social. Após a apresentação de cada uma das três metafunções, são apontadas sugestões de aplicação da teoria para a análise de diferentes gêneros, com exemplos extraídos de trabalhos com diversos tipos de corpus.

\section{Princípios básicos da LSF}

A LSF é caracterizada como uma teoria social porque parte da sociedade e da situação de uso para o estudo da linguagem; seu foco está em entender como se dá a comunicação entre os homens, a relação entre indivíduos e desses com a comunidade. Caracteriza-se também como uma teoria semiótica porque se preocupa com a linguagem em todas as suas manifestações. Procura desvendar como, onde, porque e para que o homem usa a língua, bem como a linguagem em geral, e como a sociedade o faz.

Trata-se de uma teoria que parte do significado e não da forma. Tendo em vista que a unidade semântica é o texto, seu ponto de partida (e não a oração), apresenta-se, portanto, como uma teoria da comunicação humana. Temos, então, mais dois termos importantes: texto e unidade semântica. Texto que vai desde um gesto, uma palavra, a todo um discurso. E unidade semântica porque a interação entre os indivíduos, ou mesmo de um indivíduo consigo mesmo, em sociedade, em um dado contexto, tem significado. 
A interação entre língua, linguagem e sociedade coloca a LSF num contexto pós moderno no qual adquire um conceito diferente daquele tradicionalmente dado à linguística. Na linguística tradicional, parte-se da estrutura, da forma, - da língua -, separado do uso ou do significado, portanto, não da linguagem como um todo. A LSF também se preocupa com a estrutura, uma vez que o estudo da estrutura da comunicação é necessário para se entender o significado das mensagens geradas na linguagem. Porém, de acordo com essa teoria, o significado é determinador da forma. Conforme as necessidades dos falantes em contextos específicos, são as escolhas no que tange às formas que expressam os significados desejados. Componentes fundamentais do significado na linguagem são, portanto, componentes funcionais.

É isso que explica o estudo da estrutura da língua, portanto, de toda a linguagem, a partir dos significados e não a partir dos elementos estruturais. Assim, ao conceber sua gramática, Halliday propôs uma divisão da linguagem em metafunções que resumem os três tipos de significados que podem ser realizados e que decorrem dos contextos - social e cultural - em que a interação ocorre.

Os três grandes grupos de significados são a base para a análise de como os significados são criados e entendidos, porque permitem o estabelecimento de uma relação entre as funções, ou significados, e determinados tipos de estrutura. Nessa perspectiva, a expressão dos três tipos de significados é realizada por certos elementos da lexicogramática.

O significado experiencial é realizado por escolhas feitas no sistema de transitividade. Os processos verbais, assim como os participantes e as circunstâncias do evento comunicativo, veiculam a experiência de mundo do falante.

O segundo tipo de significado, o interpessoal, é realizado por escolhas feitas nos sistemas de modo e modalidade. O primeiro sistema determina os papéis que os participantes de uma interação representam e atribuem ao seu interlocutor. O sistema de modalidade indica a posição do falante a respeito de sua mensagem e de sua relação com seu interlocutor. 
O terceiro tipo de significado, o textual, é realizado por decisões que o falante toma com relação à distribuição da informação; que componentes de sua mensagem escolhe para ser tema/rema e dado/ novo. São escolhas que têm a ver com a construção da mensagem.

A respeito dos significados que são transmitidos durante a comunicação, Halliday argumenta que,

"The meanings are woven together in a very dense fabric in such a way that, to understand them, we do not look separately at its different parts; rather, we look at the whole thing simultaneously from a number of different angles, each perspective contributing towards the total interpretation. That is the essential nature of a functional approach.” (Halliday \& Hasan, 1989:23)

Halliday mostra que há uma relação sistemática entre a organização da língua, isto é, entre os três tipos de significados que ela está estruturada para fazer, e os elementos contextuais. Segundo ele, três são as variáveis que devem caracterizar um contexto:

- o campo do discurso, ou sobre o que a interação trata;

- as relações do discurso, ou os papéis desempenhados, e as relações interpessoais presentes no discurso;

- o modo do discurso, ou como a língua é organizada para atingir os objetivos aos quais se destina.

Há entre os elementos do contexto e as realizações linguísticas uma relação dialética, haja vista a possibilidade de um ser previsível a partir do outro. Assim, Halliday demonstra ser possível identificar partes do sistema da linguagem que concernem à realização de cada tipo de informação contextual. Segundo Halliday, cada uma dessas variáveis contextuais está relacionada a uma das metafunções descritas anteriormente:

- o campo do discurso é expresso pela metafunção ideacional;

- a relação entre os participantes é expressa pela metafunção interpessoal;

- o modo do discurso é expresso pela metafunção textual.

A relação entre as variáveis de contexto, as metafunções e as realizações linguísticas podem ser visualizadas no quadro abaixo. 


\begin{tabular}{|c|c|c|}
\hline Variáveis de contexto & Metafunções & Realizações lexicogramaticais \\
\hline Campo & Ideacional & Transitividade \\
\hline Relações & Interpessoal & Modo e Modalidade \\
\hline Modo & Textual & Tema e Rema \\
\hline
\end{tabular}

As metafunções, como se pode observar no quadro em destaque, realizam-se a partir das necessidades da situação, ou seja, das características do contexto de situação de fala, o registro. A situação de fala, por sua vez, está inserida em um contexto de cultura específico. É a partir dos elementos da cultura que o falante seleciona os elementos de seu texto. O homem, situado histórica e socialmente numa cultura, seleciona, a partir dessa cultura, o modo como vai produzir texto, a forma como interagirá com os participantes da interação, tendo em vista um conhecimento, um conteúdo experiencial que será realizado com a seleção que fará. Textos terão características diferentes dependendo dos participantes e da finalidade a que sirvam. Há tipos de situação em que os participantes são mais ou menos previsíveis, como por exemplo, em um contexto acadêmico, escolar, na produção de narrativas, ou em qualquer contexto de situação em que a produção seja mais ou menos estruturada. Podemos falar, assim, em artigos científicos, em narrativas, em narrativas voltadas para crianças, em narrativas de assalto etc. ${ }^{1}$

A grande maioria de estudos no Brasil é contextualizada em termos de cultura e situação. Tanto os principais centros tradicionais de pesquisa sistêmica (UFSC, PUCSP e logo a seguir a UFMG) quanto os múltiplos centros novos em outras regiões do país se preocupam com a linguagem em sociedade, portanto, trabalham diretamente com situações específicas e participantes claros. Suas pesquisas e atuação vão desde o ensino nas mais diversas formas, ação social em geral, trabalhando também com multimodalidade, as mais variadas mídias,

1. Para alguns estudos de gênero em sistêmica ver Martin (1992), Martin \& Rose (2008), Christie (2002), Christie e Martin (1997). 
tradução, literatura, para mencionar as principais áreas. Frequentemente esse trabalho se dá interagindo com Linguística de Corpus.

Citaremos alguns trabalhos, diferentes manifestações de cultura com meios diferentes, personagens variados, reais ou imaginários, e que têm funções claramente determinadas, específicas, portanto gêneros na concepção de Swales (1990), Bakhtin (1997) e Martin (1992). Dois trabalhos, estudando produção escrita de crianças de contextos socioeconômicos, escolas e séries diferentes, são de Trindade (2010) e Barbosa (2009). Trata-se de pesquisas que, independentemente, procuraram fatores que explicassem diferenças e semelhanças em relação a esses parâmetros a partir das categorias textuais propostas por Martin e Rose (2008).

Muitos estudos na área do trabalho foram conduzidos tais como: Barbara e Berber Sardinha (2003), estudando reuniões de negócios; Souza (1997), analisando cartas de pedido de emprego; Batista (1998), examinando emails trocados internamente em uma empresa; e Vian Junior (1997), analisando vídeos institucionais.

Cada uma dessas manifestações da cultura assume formas diferentes devido a condições semânticas e situacionais diferentes, ou seja, as variáveis de registro, representadas na Figura 1, seguindo a proposta teórica da Gramática Sistêmico Funcional. A Figura 1, apresentada a seguir, mostra a sociedade, a cultura, no círculo maior, que nos permite, a partir dos elementos da situação de fala, o registro, selecionar os elementos das três metafunções da lexicogramática.

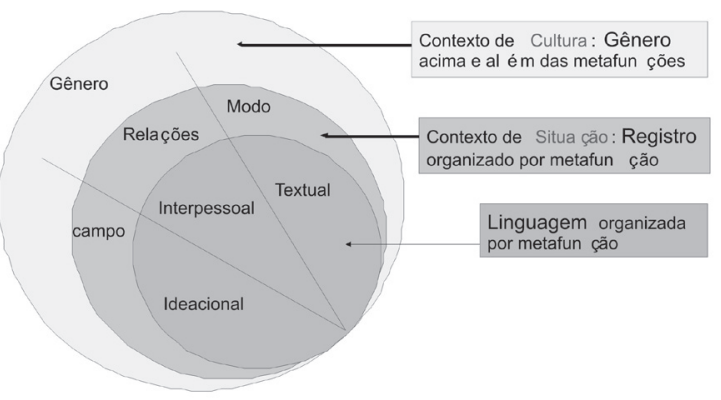

Figura 1: do contexto de cultura às metafunções 
A partir das características gerais da LSF delineadas acima, podemos fazer as seguintes perguntas: qual a importância dessa teoria para os estudos da linguagem? A quem ela serve? A que se propõe?

Em primeiro lugar, ela permite descrever a língua e a linguagem em toda sua amplitude de forma e significado. É uma teoria integrada da linguagem que atende às preocupações do Círculo de Praga, daqueles que foram os primeiros linguistas do mundo moderno abrangendo todo o ocidente, da Rússia aos Estados Unidos, em que estavam presentes, desde seu organizador Mathesius, Jakobson, antropólogos como Malinowski e Boas, a Peirce e Saussure.

É também um instrumento de análise especialmente útil a linguistas aplicados e outros cientistas preocupados em explicar fenômenos sociais, ou psicológicos, uma vez que são poucos os fenômenos, caso haja algum, que não se manifestam por meio da linguagem. Enfim, ela serve de instrumento de trabalho a todo analista da sociedade.

Trata-se de uma teoria estruturada de uma forma que permite mostrar, sistematicamente, por meio da linguagem, características vivas da sociedade ao se fazer a análise dos textos produzidos pelos seus participantes, desde textos informais de falantes anônimos a textos institucionais, sejam eles orais ou escritos, formais ou informais. É uma teoria que utiliza um método detalhado de análise de texto em contexto, que permite explicar, com um alto grau de objetividade, como os indivíduos usam a língua e como a linguagem é estruturada em seus diferentes usos para produzir significado. Por trás desse pressuposto está uma teoria probabilística da linguagem (Halliday, 1991a; 1991b).

Uma maneira de entender uma sociedade é analisar os textos por ela produzidos porque é pela linguagem que o indivíduo revela seus valores e suas representações. Não basta, no entanto, analisar, aleatoriamente, este ou aquele elemento que chame atenção. A LSF oferece um instrumento que permite investigá-la a partir da situação em que a linguagem é produzida e entendê-la a partir da função para a qual está sendo produzida tendo em vista quem a produz e para quem, quando, onde, e como a produz. 
Passemos, então, a detalhar as características da lexicogramática, mostrando, por meio de exemplos retirados de diversos trabalhos científicos, como as realizações linguísticas, analisadas sob o enfoque da LSF, fornecem pistas sobre a interação.

\section{A metafunção ideacional}

Comecemos pela manifestação de conhecimento de mundo no texto, o conhecimento das ideias, concernente à metafunção ideacional, que se relaciona à variável de campo, o campo das ideias. Assim, a metafunção ideacional da lexicogramática organiza as idéias dos indivíduos (além de representá-las). Isso nos leva à explicação do termo lexicogramática. Para a teoria sistêmico-funcional, o léxico é tão importante quanto a gramática e tem uma gramática própria. A gramática tem regras de estrutura; "gramática” no sentido tradicional. O léxico tem regras de colocação; além de um dicionário que especifica os significados dos itens, necessitamos daquilo que em inglês se chama thesaurus que é o conjunto de regras que explica as formas de realização, os contextos, de palavras em seus variados significados. (Halliday \& Matthiessen, 2004:43)

Estamos entendendo uma gramática em que o significado de mundo está integrado à forma, justamente através do léxico. Os elementos do léxico também têm uma estrutura própria, em sistêmica e em linguística do corpus, chamada colocação. Estamos partindo de um princípio de não dissociação de léxico e gramática, como partimos do princípio de uma linguagem contextualizada.

A metafunção ideacional subdivide-se em dois componentes: o experiencial e o lógico. O primeiro trata do conteúdo interno de uma oração, sua estrutura, a transitividade. Os elementos da transitividade são os processos, os participantes que são determinados pelo processo e as circunstâncias que são associadas ao processo; assim entendese que o núcleo da transitividade é o processo que é realizado por um verbo. Esses processos classificam-se em três tipos principais: os processos do ser, os do sentir e os do fazer. Esses tipos de processo 
(vide Figura 2) estão entremeados por outros três secundários: dizer, comportar-se e existir, formando um contínuo.

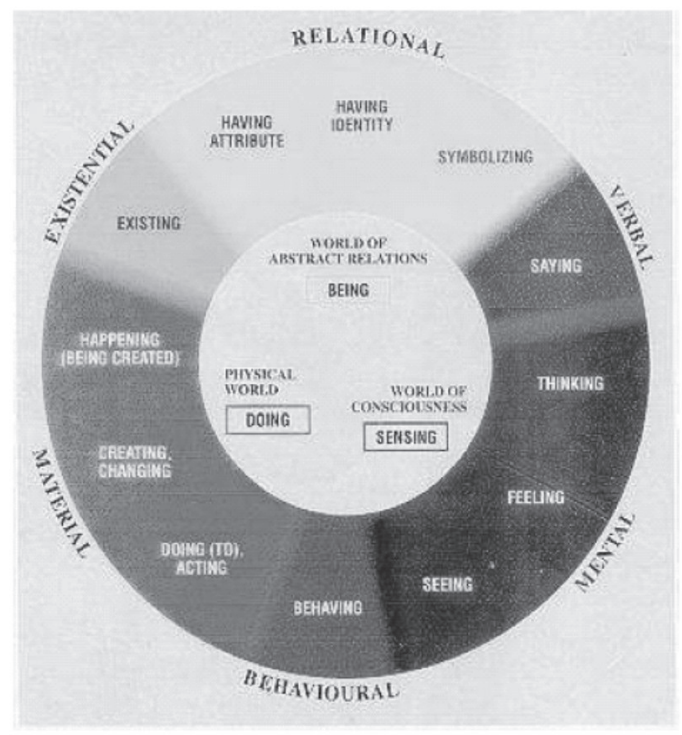

The cover of Halliday 1994

Figura 2: capa de Halliday, 1994

Como exemplo de pesquisa no âmbito da metafunção ideacional, no componente experiencial, há o trabalho de Assumpção (2008) que discute semelhanças e diferenças na representação da mulher nas sociedades brasileira e americana, em reportagens de jornais através da análise dos processos utilizados pela mídia para referirse à mulher, em diferentes áreas de atuação. A autora (2008:102) mostra ocorrências do participante mulher em que são enfatizadas suas conquistas, como abaixo:

1. mulheres conquistam cargos antes restritos aos homens.

2. Mulheres dominam universidades nos EUA.

3. Mulheres lideram (nos projetos) 
A pesquisadora chama atenção para o fato de haver um grande número de processos que representam luta (invadir, assumindo, conquistam, dominam, lideram) o que, conforme a autora, "sugerem uma representação das mulheres tentando ir contra o anteriormente estabelecido". A autora aponta também que "objetos de suas conquistas, ou seja, as metas dos processos são cargos, universidades, projetos e poder político". Esse trabalho demonstra, assim, como uma interação pode ser analisada à luz do componente ideacional da LSF.

O outro componente da metafunção ideacional, o componente lógico, trata dos significados relacionados à organização dos grupos verbais e nominais (abaixo da oração) e dos complexos oracionais e coesão textual (acima da oração). Um exemplo de trabalho com esse arcabouço teórico é Soares (2008) que analisou as revistas Speak Up, uma revista para brasileiros estudantes de inglês, e Newsweek mostrando que elas tinham características diferentes em termos de dificuldades de compreensão em virtude de diferentes usos do componente lógico. Aproveitando seu exemplo (Soares:2008:68-69), vejamos como algumas diferenças entre as duas revistas.

\begin{tabular}{|l|l|}
\hline Newsweek & $\begin{array}{l}\text { In exchange, the North would get full diplomatic recognition, } \\
\text { the promise of billions in aid from Washington and Tokyo, } \\
\text { and the stamp of legitimacy and guarantee of security that a } \\
\text { Clinton visit would bring, says Albright's former senior aide, } \\
\text { Wendy Sherman. }\end{array}$ \\
\hline Speak Up & $\begin{array}{l}\text { Timetables are flexible and the agenda of activities is defined } \\
\text { with the relevant tourist Just one meal before each start. }\end{array}$ \\
\hline
\end{tabular}

Em Speak Up, em uma cláusula relativamente curta, há uma única coordenação unindo duas orações. O trecho retirado de Newsweek, no entanto, tem uma cláusula mais longa que, para visualização, pode ser decomposta em:

- In Exchange, um conector, que liga a cláusula ao parágrafo anterior (não relevante aqui); 
- The North, o beneficiário;

- would get, o processo seguido de três atributos que são nominalizações, e não substantivos comuns, em relação paratática (coordenada em termos tradicionais), (a primeira realizada por vírgula e a segunda por $\underline{\text { and }}$ ) a saber:

- full diplomatic recognition,

- the promise of billions in aid from Washington and Tokyo

- and the stamp of legitimacy and guarantee of security that a Clinton visit would bring.

A essa complexidade acrescente-se mais uma: duas das nominalizações contêm and a primeira relacionando dois substantivos e a segunda duas nominalizações, resultando, mesmo com o uso de estruturas paratáticas, com o mesmo elemento and, uma cláusula, além de longa, muito mais densa que o exemplo retirado da outra publicação.

Com um trecho retirado de um artigo científico da área de meio ambiente, mostramos abaixo outra análise no âmbito do componente lógico, agora tratando de referência e não de coesão, como acima. Vejamos o exemplo abaixo, retirado do corpus do projeto Systemics Across Languages (SAL) ${ }^{2}$.

4. $\underline{\mathrm{O}}$ homem $^{3} \underline{\text { metropolitano }}^{1},{ }^{[1]}$ premido $^{5}$ pelo exíguo ${ }^{[2]}$ e poluído espaço ${ }^{2},{ }^{[2]}$ que sempre é dos outros ${ }^{[3]}$, pelo limitado tempo que ${ }^{[1]}$ é obrigado a ${ }^{[1]}$ viver ${ }^{[5]}$ pelo sonho que não é mais colorido, ${ }^{[5]}$ pela velocidade dos acontecimentos e ${ }^{[5]}$ pela irreversibilidade ${ }^{[1]}$ sentida e ${ }^{[1]}$ vivida no cotidiano, certamente, ${ }^{[1]}$ se sente $^{4}$ mais impotente, ${ }^{[1]}{ }^{[4]}$ mais amargo $\mathrm{e}^{[1][4]}$ menos criativo. (MA - TXT 01)

Trata-se de uma oração retirada da introdução de um artigo científico, portanto, nesse momento está sendo colocado um problema. $\mathrm{Na}$ oração, são introduzidos cinco elementos anafóricos - homem, homem metropolitano, espaço, sente e premido representados pelos

2. Foi retirado do corpus de português do Brasil do projeto SAL (Systemics Across Languages). 
números sobrescritos, sendo o homem metropolitano repetido várias vezes. Esse uso de anáfora - tantos elementos anafóricos em uma mesma oração - é bem característico de um discurso elaborado, especialmente escrito. Como mencionaremos também abaixo, ao tratar da metafunção textual, o foco no componente lógico da metafunção textual é importante para o ensino em geral e em especial na compreensão e produção textual. Aliás, mesmo sem menção à gramática sistêmico funcional, esta área do trabalho de Halliday tem sido reconhecida em muitos trabalhos sobre gramática ou texto.

\section{A metafunção interpessoal}

Vimos acima a linguagem manifestando o conhecimento de mundo do falante, da sociedade. A metafunção interpessoal parte da variável de contexto de situação Relações. Ela representa os falantes, suas intenções, relações; é através da metafunção interpessoal que se manifesta a interação entre os participantes da situação e deles com a sociedade, como interagem, o grau de distância/proximidade ou de poder/solidariedade existente entre eles, a responsabilidade que assumem quanto à mensagem que transmitem, se o fazem de maneira assertiva/categórica, ou não. Tem portanto a ver com a mensagem enquanto $\mathrm{Na}$ gramática funcional, esse significado materializase na estrutura da língua pelas escolhas feitas quanto ao modo e à modalidade.

Pesquisa sobre imagem pública em cartas de reclamação estabelecendo um paralelo entre escolhas dos sistemas de modo e modalidade e a necessidade de preservação, ou não, da face dos participantes, Macêdo (1999) constatou que o cliente ameaça a face da empresa ao fazer uso de modalidade alta ao se refere às obrigações e deveres por ela não cumpridos e às obrigações a ele impostas. Nos exemplos abaixo (Macêdo, 1999:109), o cliente usa o operador modal 'dever' expressando inação da empresa quanto ao que ele considera obrigação dela. 
5. Eu estava ausente, deveriam ter tentado me localizar, mas não o fizeram eficazmente

6. quando finalmente consegui a façanha de tapá-lo como se deve usando da intervenção até do prefeito

7. me vejo vergonhosamente obrigado a comprar as mesmas que deveria ter recebido em casa

A empresa, por sua vez, apresenta exemplos de utilização do modal 'poder' para referir-se a ação futura. É potencialidade porque a empresa procura mostrar capacidade em fazer algo no futuro que venha satisfazer o cliente. Nesses casos, 'poder' geralmente vem em uma oração de finalidade

8. Aproveitamos a oportunidade para enfatizar a importância de recolher os produtos defeituosos, pois só através de análise pormenorizada poderemos compreender a falha

Partindo de exemplos de falas avulsas retiradas de Barbara e Silvestre (2007) que estuda reuniões de negócios em Portugal e Brasil, vamos aproveitar para sucintamente apontar a importância de outros aspectos do estudo da metafunção interpessoal. O elemento interativo nesse estudo enfocado é o marcador discursivo. Os exemplos que arrolamos são fragmentos da fala de dois chefes de equipes de trabalhadores adultos, independentes, em postos não assalariados; mostram, características diferentes marcadas por elementos de interpessoalidade (em negrito).

\section{A: agora veja só o seguinte, ...}

A: ... então veja bem ele está tendo ... ele ....

A: Teria que estar com desenhos prontos até o final de outubro, quer dizer, desenho pronto então pro

A: Ó! Raul, Raul, espera aí, espera aí. A campanha não é tua.

B: Bem, mais uma vez, não se esqueçam. .... Eu não queria ... o mês como fiz o mês passado. Tomem bem nota.

B: Ah, bom, voltando à nossa conversa, passem o negócio a pente fino, não deixem... 
B: tá bom? Vejam bem os negócios que têm com vocês. Senão vamos ter outro mês...

B: era uma boa você ir lá falar de novo com...

No contexto das reuniões analisadas, A, ao contrário de B, ao fazer observações críticas as faz diretamente usando marcadores discursivos mais diretivos (como veja bem ou $\mathrm{O}$ !), verbos no singular ou imperativos (veja); B, ao contrário, usa formas menos diretivas, como interrogativas, ou seja formas de sugestão (tá bom? Vejam...), ou rememoração (voltando à nossa conversa), passado (Eu não queria, era uma boa), a forma informal de condicional passado.

Tivemos aqui apenas uma pequena amostra do que pode ser feito a respeito da relação entre os participantes. Há ainda outras possibilidades de pesquisa no âmbito dessa metafunção. Não entraremos aqui, por exemplo em uma área muito importante da interpessoalidade e que tem sido muito desenvolvida a partir da última década do século XX, a avaliatividade (Eggins \& Slade, 1997; Hunston \& Thompson, 2000; Martin \& White, 2005; Sartin, 2008; Sobhie, 2008; Vian jr., 2009; Pereira, 2010).

\section{A metafunção textual}

A variável modo é responsável pela organização do texto, sua tessitura. Ela está relacionada ao significado textual que é realizado por decisões que o falante toma com relação à distribuição da informação; que componentes de sua mensagem escolhe para ser tema/rema e dado/novo. São escolhas que têm a ver com a construção da mensagem. Halliday classifica as metafunções como estudo da língua(gem) no nível das orações e a metafunção textual como o estudo da organização das orações no nível do texto. Essa metafunção é constituída do Tema, o ponto de partida da oração, e do Rema.

Do ponto de vista do linguista teórico, ela é importante na distinção, por exemplo, entre línguas como português e inglês que 
diferem em termos de regras de omissão de sujeito da oração (Gouveia e Barbara, 2004). Para professores de línguas e, por consequência, para o analista do discurso que lhes fornece subsídios, é de fundamental importância para explicar fenômenos de textualidade em gêneros diferentes, basicamente em discurso escrito, e em como ensiná-los.

Como exemplo de trabalho relacionado ao ensino e aprendizagem de línguas no ensino básico, temos a dissertação de Sousa (2007) que estudou a produção escrita de alunos de um curso preparatório, com o intuito de verificar como esses textos são organizados. Partindo de dois grupos de textos, aqueles avaliados positivamente pelos professores e aqueles avaliados como insatisfatórios, a pesquisadora chegou a padrões que caracterizaram os dois grupos. Abaixo temos um texto do grupo de produções satisfatórias (2007:76), com as escolhas temáticas em negrito.

\section{Mundo de informações}

As mudanças provocadas pela tecnologia informacional ficam mais evidentes a cada dia. Em poucos anos, o mundo foi interligado pela informação, que se tornou uma importante ferramenta, tanto nos negócios quanto na educação.

Com toda essa informatização, era de se esperar que surgissem dilemas sobre o quão benéfico seria esse excesso de tecnologia. Em muitos setores, como na educação e na cultura, é imprescindível a globalização da informática, pois é um meio de divulgar o conhecimento, que sem dúvida, é fundamental. Mesmo em outras áreas, muito pode ser aproveitado dos avanços tecnológicos e da imensa quantidade de informação de que se dispõe.

Existe, como já citado, o outro lado da história. Com todos esses avanços, veio junta uma espécie de "sedentarismo mental". Sua causa é um excesso de conhecimento que, por ser um excesso, pode acabar se tornando inútil, caso não seja devidamente utilizado. É uma prova de que é necessário um filtro de informações, uma dosagem do que pode enriquecer o homem e o que criará uma geração de robôs, homens com muita informação, porém sem raciocínio.

É difícil prever como será o mundo e quais serão as mudanças que toda essa informatização pode implantar. É certo, porém, que a tecnologia é uma alavanca para a evolução e, se utilizada com sabedoria, pode impulsionar o homem a grandes feitos, como no passado. 
Com esse trabalho, a autora visou suscitar reflexões sobre o que pode ser feito para melhorar a prática pedagógica dos professores de Língua Portuguesa no que se refere à produção escrita de seus alunos, no nível da organização textual.

\section{Uma palavra final}

Vimos, com este trabalho, que a Linguística Sistêmico Funcional tem uma proposta teórica e metodológica que permite ao analista do discurso trabalhar nas mais diversas linhas de pesquisa, com diferentes tipos de corpus, em diversos contextos. A teoria tem como foco o homem, ancorado no espaço que ocupa na sociedade e em constante interação com outros homens, e mostra que as escolhas linguísticas feitas por ele estão estreitamente relacionadas com suas intenções comunicativas. Desse modo, a compreensão que se pretende ter desse homem passa necessariamente por uma gramática como a de Halliday na qual a forma está sempre a serviço de uma função.

Nesta palavra final, gostaríamos de lembrar que a LSF está atuante no Brasil desde o final da década de 1980, tendo-se iniciado na UFSC com a Professora Rosa Konder, sem dúvida a primeira sistemicista brasileira, e na PUCSP com a Professora Antonieta Celani que, com seu Projeto Ensino de Inglês Instrumental em Universidades Brasileiras, trouxe ao Brasil importantes sistemicistas como Florence Davies e Geoff Thompson. Isso desencadeou a formação de pesquisadores na área e a disseminação da LSF para outros Centros como UFMG, PUC-Rio, tendo todos contribuído para a atuação, agora, de pesquisadores em grande número de centros no Brasil e para a produção de mais conhecimento na área. Agradecemos a elas.

Recebido em: novembro de 2009 Aprovado em: dezembro de 2009 cmmacedo@ufpa.br lbarbara@uol.com.br 


\section{Referências Bibliográficas}

ASSUMPÇÃO, M. (2008) As representações da mulher profissional brasileira e norte-americana construídas pela mídia impressa. Dissertação de Mestrado. PUC-SP.

BAKHTIN, M. (1997) Estética da Criação Verbal. São Paulo: Martins Fontes.

BARBARA, L. \& C. SILVESTRE. (2007). Discourse Markers in business meetings in Brazilian and European Portuguese. V DICOEN. Nottingham.

BARBARA, L. e BERBER SARDINHA, T. (2003) A linguagem dos negócios. Intercâmbio (PUCSP), PUC/SP, v. XII, p. 253-258.

BARBOSA, M. do Rosário (2009) Conte uma história... Estudo de Gênero na Escola sob a ótica da Lingüística Sistêmico-Funcional. Tese de Doutorado. PUC-SP.

BATISTA, M. E. (1998) E-mails na troca de informação numa multinacional: $O$ gênero e as escolhas léxcico-gramaticais. Dissertação de Mestrado. PUC-SP.

CHRISTIE, F. (2002) Classroom discourse analysis: a functional perspective. London: Continuum.

CHRISTIE, F. \& MARTIN, J, R. (eds) (1997) Genre and Institutions: social processes in the workplace and school. (Open Linguistics Series) London: Pinter.

EGGINS, S. \& SLADE, D. (1997) Analysing casual conversation. London: Continuum.

GOUVEIA, C. e BARBARA, L. (2004) Marked or Unmarked, that is NOT the question. The question is: Where is the theme? Ilha do Desterro (UFSC), v. 46, p. 155-178.

HALLIDAY, M. A. K. \& HASAN, R. (1989), Language, context and text: Aspects of language in a social-semiotic perspective. Oxford: Oxford University Press. HALLIDAY, M. A. K. (1991a) Corpus studies and probabilistic grammar. In: K. AIJMER \& B. ALTENBERG (org.). English corpus linguistics: Studies in honour of Jan Svartvik. London: Longman. 
HALLIDAY, M. A. K. (1991b) 'Towards probabilistic interpretations', in: E. VENTOLA (ed.) Functional and systemic linguistics: approaches and uses, pp. 39-61, Berlin and New York: Mouton de Gruyter.

HALLIDAY, M. A. K. (1994) An introduction to functional grammar. $2^{\text {nd }}$ Edition, London: Arnold.

HALLIDAY, M. A. K. \& MATTHIESSEN, C. (2004) An introduction to functional grammar. $3^{\text {rd }}$. edition, London: Arnold.

HUNSTON, S. \& THOMPSON, G. (2000). Evaluation in Text: Authorial Stance and the Construction of Discourse. (ed.) Oxford University Press.

MACÊDO, C. M. M. (1999) A reclamação e o pedido de desculpas: uma análise semântico-pragmática de cartas no contexto empresarial. Tese de doutorado. PUC-SP.

MARTIN, J. R. \& ROSE, D. (2008) Genre relations mapping culture. London: Equinox.

MARTIN, J. R. \& WHITE, P. R. R. (2005) The language of evaluation: appraisal in English. New York: Palgrave Macmillan.

MARTIN, J. R. (1992) English Text: system and structure. Amsterdam: Benjamins.

PEREIRA, E. B. (2010) O professor avaliado em textos jornalísticos: análise da avaliatividade em reportagens de Veja e Isto é. Dissertação de Mestrado. UFPA.

SARTIN, F. (2008) Avaliatividade no discurso de professores universitários. Tese de Doutorado. PUC-SP.

SOARES, J. O. (2008) Estudo sistêmico-funcional da estrutura lógica de artigos de revista em inglês. Dissertação de Mestrado. PUC-SP.

SOBHIE, M. T. (2008) Análise comparativa de avaliação em press releases e notícias. Tese de Doutorado. PUC-SP.

SOUSA, R. S. N. de (2007) A escolha temática em redações de alunos de curso preparatório. Dissertação de Mestrado. UFPA.

SOUZA, S. M. P. (1997) A Organização da Mensagem em Anúncios e Cartas de Pedido de Emprego: Um Estudo Transcultural. Tese de Doutorado. PUC-SP. 
SWALES, J. (1990) Genre Analysis: English in academic and research settings. (Cambridge Applied Linguistics) Cambridge: Cambridge Univeristy Press.

TRINDADE, Z. (2010) A lenda do açai recontada por alunos da escola fundamental: análise da estrutura, escolhas lexicogramaticais coesivas e avaliatividade. Tese de Doutorado. PUC-SP.

VIAN JR., O. (2009). O sistema de avaliatividade e os recursos para gradação em Língua Portuguesa: questões terminológicas e de instanciação. DELTA. Documentação de Estudos em Lingüística Teórica e Aplicada, v. 25:1, p. 99-129.

VIAN JR., O. (1997). Contexto de gêneros e análise de textos de vídeos institucionais. Dissertação de Mestrado. PUC-SP. 